\title{
Jim Pawley and the Flowering of Confocal Microscopy
}

\section{Martin Wessendorf}

\section{University of Minnesota, Minneapolis, Minnesota, United States}

Jim Pawley was well-known as the editor of the Handbook of Biological Confocal Microscopy, which has lived up to its name and has gone through three (...or is it four?) editions. The Handbook has lived up to its name, due to Jim's vision for it and his ability to recruit excellent people to contribute to it.

What are less known are Jim's contributions to microscopy through his postings on the Confocal Microscopy Listserv. For those who are unfamiliar with it, the Confocal Listserv is an old-fashioned email listserv in which postings from any member are shared with all. The Confocal List was, and still is, frequently used by those who have questions about confocal microscopy or technical questions about microscopy in general. During the 27 years in which he was an active member of the Confocal List, Jim posted over 500 times, almost always in response to another person's question. The topics he addressed ranged from recommendations regarding video cameras ("SIT vs. CCD" in one of his first posts), to fixation for super-resolution studies (in his last post on the List). In between he touched on -in a concise and articulate manner--almost every technical aspect of microscopy: Koehler illumination, photomultiplier and camera technologies (--a perennial favorite and one that allowed him to touch on one of his favorite subjects: the effect of photon statistics on images), spinning-disc confocal, measurement of resolution, condensers, illumination sources, image deconvolution...the list goes on and on. Jim was generous with his knowledge. Especially in later years, he also wasn't above using his answers on the List as an opportunity to give "The Handbook" (as he referred to it) a plug. It's good that he did. It was a reminder to all of us in the field that many, many of the questions a person might have about confocal microscopy had already been answered within its pages. And thus, though we have lost the person, we still have the product of his labor. Through it, Jim will continue to live a productive life for many more years.

\section{References}

Handbook of biological confocal microscopy, James B Pawley, Ed.; Revised edition, New York : Plenum Press, 1990

Handbook of biological confocal microscopy, James B Pawley, Ed. 2nd edition, New York : Plenum Press, 1995

Handbook of biological confocal microscopy, James B Pawley, Ed. $3^{\text {rd }}$ edition, New York, NY : Springer, 2006

Confocal Listserv: https://lists.umn.edu/cgi-bin/wa?A0=CONFOCALMICROSCOPY 